\title{
Effect of Martensite structure in Graphitization Process in Hypereutectoid steel
}

\author{
S.A.Rounaghi ${ }^{\mathrm{a} 1}$, A.R.Kiani-Rashid ${ }^{1}$, F.Fazeli $^{2}$ \\ ${ }^{1}$ Department of Materials Engineering, Ferdowsi University of Mashhad, Mashhad, Iran. \\ 2 Department of Materials Engineering, Faculty of Engineering, The University of British Columbia, \\ Vancouver, BC, Canada.
}

\begin{abstract}
Graphitization process in steels is referred to the decomposition of meta-stable cementite phase to more stable phases of graphite and ferrite. In steels this transformation often occurs in the range of $600-700{ }^{\circ} \mathrm{C}$. In common commercial steels the occurrence of graphitization process requires long periods of time due to the lack of carbide stabilizer elements such as chromium and manganese. Based on experimental observations, the initial microscopic structure of steels before graphitization has a considerable effect on shortening the time of this phase transformation. In this respect a structure with martensite matrix is identified as one of the best structures for making graphitized steels. However the way of effect and kinetic investigation of graphitization transformation of this structure is less performed by researchers. In this study graphitization behavior from martensite structure in comparison with other structures is investigated by using dilatometric tests, optical microscopic and scanning electron microscope micrographs.
\end{abstract}

\section{Introduction}

Graphitization process in steel occurs during the decomposition of cementite phase to ferrite and graphite [1-7]. Although graphite is a stable type of carbon [8], the meta-stable phase of cementite is often observed in commercial steels which show the lack of reaching to equilibrium conditions or the presence of carbide stabilizer alloying elements. Graphitization from industrial steels containing high percentage of manganese and chromium requires long periods of time which is not economically possible [9-12].

Graphite is identified as one of the best solid lubricants whose presence in the final structure is a factor in improving wear resistance, machinability and self-lubricating of ferrous alloys [13]. Graphite is observed as the main phase in the structure of most of cast irons. In this respect we can refer to considerable effect of graphite particles on machinability, vibration absorption and shock resistance in grey irons [14]. Also for ductile irons the presence of graphite nodules results in improve of toughness and increase of their strength compare to other cast irons [14]. In addition, considerable mechanical and physical changes can be made by forming bainite matrix in this set of cast irons by austempering process $[15]$.

One of the most significant advantages which can be considered for graphitized steel structures is an alternative for steels containing sulphur and lead used in automotive industries. This group of steels has distractive bio-environmental effects due to the addition of sulphur and lead [16].

Based upon experimental observations [4-6] martensite and bainite structures [17] are reported as the most susceptible structures for graphitization in steel. Also based on researches by He et al, cementite particles play a key role in the nucleation of graphite nodules in the first stages of annealing. In addition, the formation of transformational carbides rather than cementite from martensite in the first stages of annealing causes delay in graphitization process from this structure compare to bainite structure [17-18].

Acceleration in graphitization from martensite structure is basically related to the changes of solid solution and carbide phase during quenching process. In addition, structural defects from martensite structure play a very important role in accelerating this phase transformation [19-21]. In this respect Pogrebnoi et al performed some tests in order to investigate the effect of crystal defects on graphitization transformation in white iron which indicates the direct effect of these defects on increasing the number of graphite particles [22].

\footnotetext{
as.a.rounaghi@gmail.com
}

This is an Open Access article distributed under the terms of the Creative Commons Attribution-Noncommercial License (http://creativecommons.org/licenses/by-nc/3.0/), which permits unrestricted use, distribution, and reproduction in any noncommercial medium, provided the original work is properly cited. 
Despite the researches on graphitization behavior of white iron, the investigation of this transformation in steels is less followed by researchers, so with respect to the length of graphitization period in industrial low-alloy steels, the investigation of accelerating factors of this transformation from kinetic viewpoint can help considerably the decrease of the period of this process in future researches.

\section{Experimental}

The steel used in this research is a low-alloy hypereutectoid one with the commercial name of CK100 whose chemical composition is presented in table 1. The microstructure of the as-received steel (specimen No. 1) includes ferrite and spherical carbides (figure 1). Table 2 presents the different types of heat treatments applied on the experimented specimens according to their numbers.

Table 1. Chemical composition of CK100 steel (weight percent).

\begin{tabular}{|c|c|c|c|c|c|c|c|c|c|c|}
\hline Steel & $\mathrm{C}$ & $\mathrm{Si}$ & $\mathrm{S}$ & $\mathrm{P}$ & $\mathrm{Mn}$ & $\mathrm{Ni}$ & $\mathrm{Cr}$ & $\mathrm{Mo}$ & $\mathrm{Cu}$ & $\mathrm{Al}$ \\
\hline $\mathrm{CK} 100$ & 0.949 & 0.213 & 0.012 & 0.017 & 0.339 & 0.047 & 0.061 & 0.008 & 0.076 & 0.017 \\
\hline
\end{tabular}
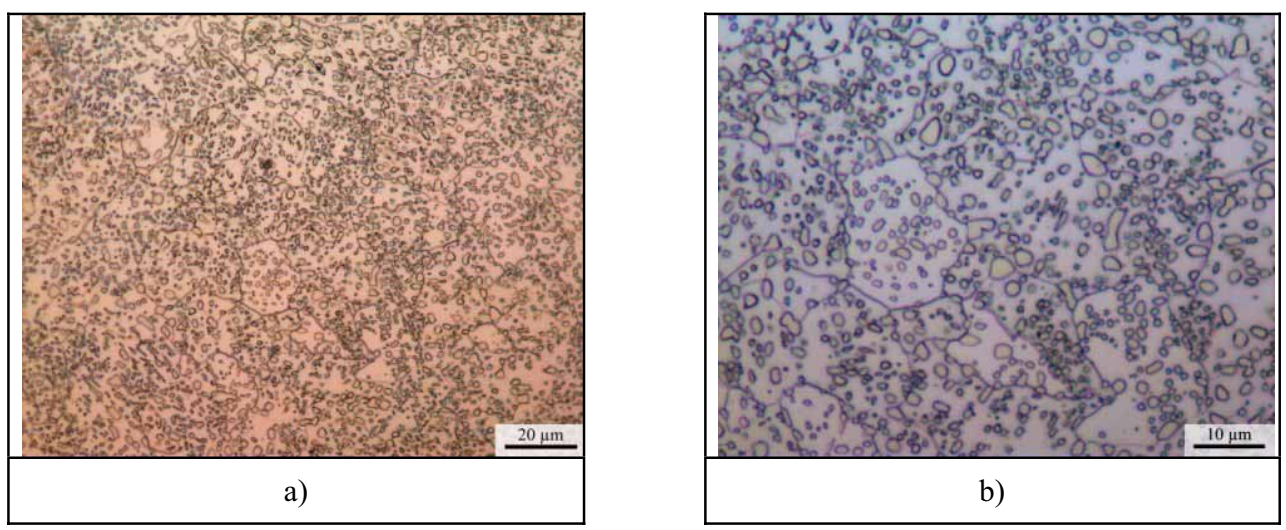

Fig. 1. a, b) Primary steel structure (as received) consists of ferrite with spheroidized carbides in two different magnifications.

Table 2. Heat treatment cycles applied on experimented specimens.

\begin{tabular}{|c|c|}
\hline Specimen & Heat treatment cycle \\
\hline 1 & As received \\
\hline 2 (Dilatometric test) & $900^{\circ} \mathrm{C}, 20 \mathrm{~min} \rightarrow$ Salt solution quenched $\rightarrow$ Graphitized at $670^{\circ} \mathrm{C}$ \\
\hline 3 (Dilatometric test) & $900^{\circ} \mathrm{C}, 20 \mathrm{~min} \rightarrow$ Water quenched $\rightarrow$ Graphitized at $670^{\circ} \mathrm{C}$ \\
\hline 4 (Dilatometric test) & $900^{\circ} \mathrm{C}, 20 \mathrm{~min} \rightarrow$ Oil quenched $\rightarrow$ Graphitized at $670^{\circ} \mathrm{C}$ \\
\hline 5 (Dilatometric test) & $900^{\circ} \mathrm{C}, 20 \mathrm{~min} \rightarrow$ Water quenched $\rightarrow$ Graphitized at $670^{\circ} \mathrm{C}$ for 6.5 hrs \\
\hline
\end{tabular}




\begin{tabular}{|c|c|}
\hline 6 (Dilatometric test) & $900^{\circ} \mathrm{C}, 20 \mathrm{~min} \rightarrow$ Water quenched $\rightarrow$ Graphitized at $670^{\circ} \mathrm{C}$ for $12 \mathrm{hrs}$ \\
\hline 7 (Dilatometric test) & $900^{\circ} \mathrm{C}, 20 \mathrm{~min} \rightarrow$ Water quenched $\rightarrow$ Graphitized at $670^{\circ} \mathrm{C}$ for $60 \mathrm{hrs}$ \\
\hline 8 & $900^{\circ} \mathrm{C}, 20 \mathrm{~min} \rightarrow$ Air cooled $\rightarrow$ Graphitized at $670^{\circ} \mathrm{C}$ \\
\hline 9 & As received $\rightarrow$ Graphitized at $670^{\circ} \mathrm{C}$ \\
\hline
\end{tabular}

The dilatometric test was done by Linseis machine model 2171 and cylindrical dilatometric specimens are prepared from the as-received steel with diameter and length of $4 \mathrm{~mm}$ and $18 \mathrm{~mm}$, respectively. For making the martensite structure, the dilatometric specimens were first austenized for $20 \mathrm{~min}$ in $900^{\circ} \mathrm{C}$ in electrical furnace and then immediately quenched in ambient temperature in three different environments of brine (10 $w t \% \mathrm{NaCl}$ ), water and oil in order to investigate the effect of quenching environment. The dilatometric test was done isothermally on these specimens in these three environments in $670^{\circ} \mathrm{C}$.

In order to compare the effect of martensite structure during the graphitization transformation, the process was investigated from two structures of the as-received steel (specimen No. 1) and the pearlitecementite steels (specimen No.7). Also the size of these specimens was selected similar to dilatometric specimens. The pearlite-cementite steels were made by austenizing the as-received steel for $20 \mathrm{~min}$ in $900^{\circ} \mathrm{C}$ and then cooling the specimens outside the furnace in air. Also the graphitization temperature was considered as $670^{\circ} \mathrm{C}$ for non-martensitic structures. Specimens No. 5, 6 and 7 were made from dilatometric test on specimen No. 3 in different annealing times. Especially specimen No. 5 was extracted from the first changes in length after 6.5 hours in the dilatometric specimen.

In order to prevent decarburization of specimens during austenizing and during the long period of annealing, the surface of al of the specimens was covered with an anti-carburizing layer. In addition to this layer, other specimens except the dilatometric ones were put in a container having cast iron particles.

In order to perform metallographic investigation of the microstructure, all of he parts were sectioned and then microscopic micrographs were prepared from their central regions after surface preparation and etching with $2 \%$ natal.

In Razi Metallurgical research Center, Tehran, SEM and EDX micrographs were prepared with the maximum voltage of $30 \mathrm{kV}$ by TESCAN and Data analysis was done by Origin 7.5 graphing software.

\section{Results and Discussion}

Figure 2 shows the dilatometric diagram of graphitization transformation from martensite structure for specimen No. 3. As we can see, the shape of this figure agrees well with the equation below:

$$
\mathrm{X}=1-\exp \left(-\mathrm{k}\left(\mathrm{t}-\mathrm{t}_{\text {incubation }}\right)^{\mathrm{n}}\right)
$$

In this equation called Johnson-Mehl-Avrami [23, 24], $\mathrm{X}$ is the volume percent of transformation, $\mathrm{t}$ is the time, $\mathrm{t}_{\text {incubation }}$ is the incubation time, $\mathrm{k}$ is a temperature-dependent index and $\mathrm{n}$ is the reaction exponent. By analyzing data that has been extracted from dilatometric test, we can find a function that can be fitted in dilatometric diagram (figure 3). Equation 2 explains this function:

$$
\Delta \mathrm{L}=15.142\left(1-\exp \left(-\left(0.00095 \mathrm{t}_{\mathrm{g}}\right)^{1.44}\right)\right.
$$

In this equation $\Delta \mathrm{L}$ is length change and $\mathrm{t}_{\mathrm{g}}$ is $\mathrm{t}-\mathrm{t}_{\text {incubation. }}$. By comparing equations 1 and 2 , value of $\mathrm{n}$ can be concluded about 1.4 which shows the diffusion-controlled nucleation and growth [24,25]. Figure 4 indicates the graphitized structure of specimen No.7. By investigating the graphitization behavior of specimens No. 8 and 9 for 75 hours in $670^{\circ} \mathrm{C}$ by optical Microscope, no graphite is observed in their structures, but after 110 hours graphite particles are formed in these structures (figures $5 \mathrm{a}$ and $\mathrm{b}$ ). According to figures $5 \mathrm{a}$ and $\mathrm{b}$ graphite particles in figures 8 and 9 have a larger size, uneven distribution 
and limited number compare to specimen No. 4 (figure 4). By analyzing the Optical Microscope pictures, the surface area percent of graphite in specimens No. 7, 8 and 9 is calculated as $3.41,0.14$ and 0.15 respectively which shows the considerable effect of martensite structure on the amount of graphite formed compare to other structures.

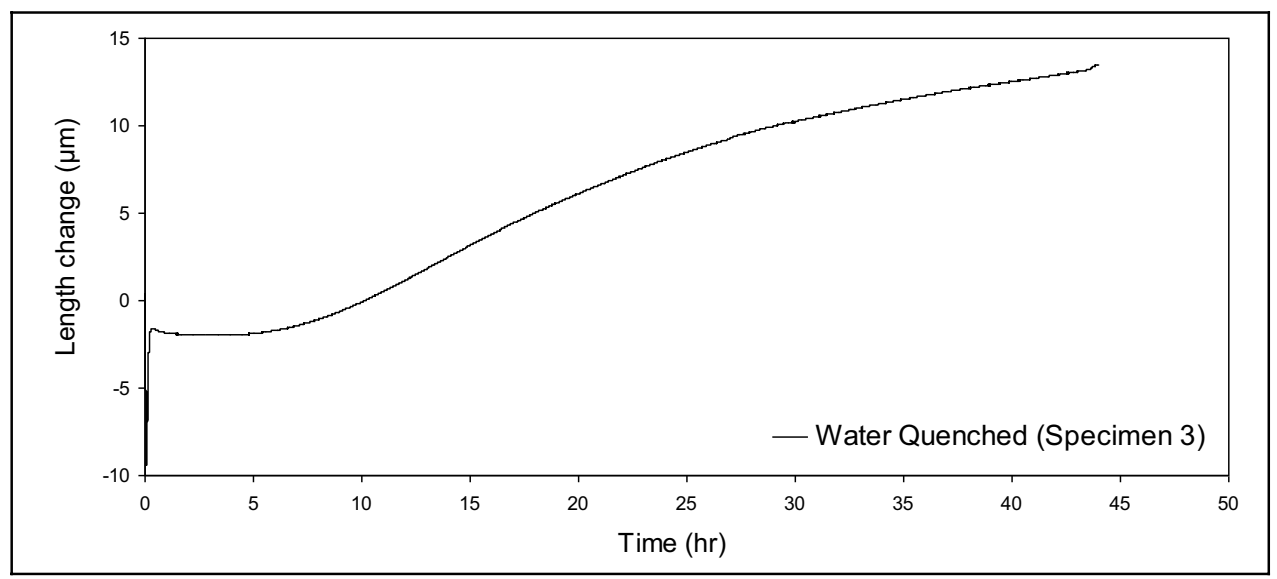

Fig. 2. Dilatometric diagram for graphitized specimen from water quenched martensitic structure (related to specimen No. 3)

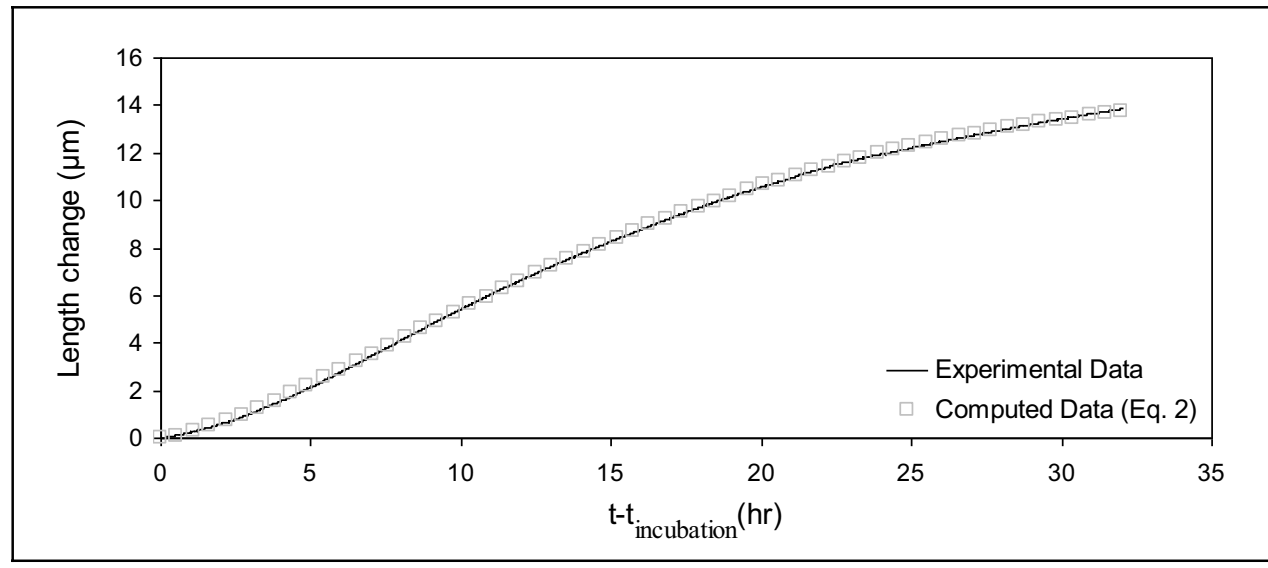

Fig. 3. Experimental and computed curves that have been extracted from dilatometric and Origin respectively.
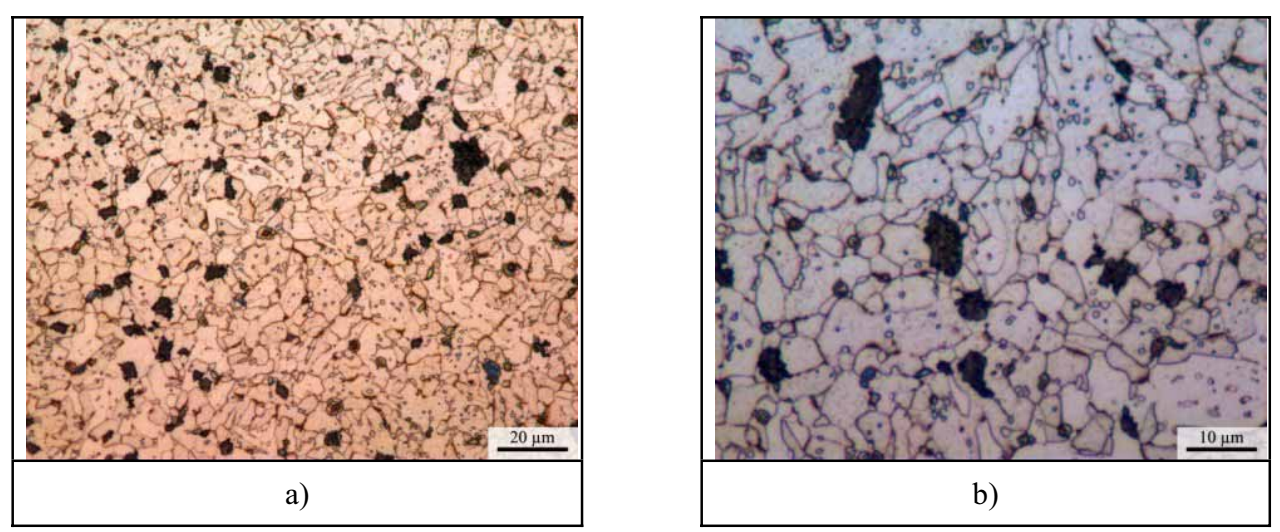

Fig. 4. a) Structure of graphitized steel after annealing at $670^{\circ} \mathrm{C}$ for $60 \mathrm{hrs}$ from primary martensitic structure (related to specimen No.4). b) The same structure with more magnifies. 

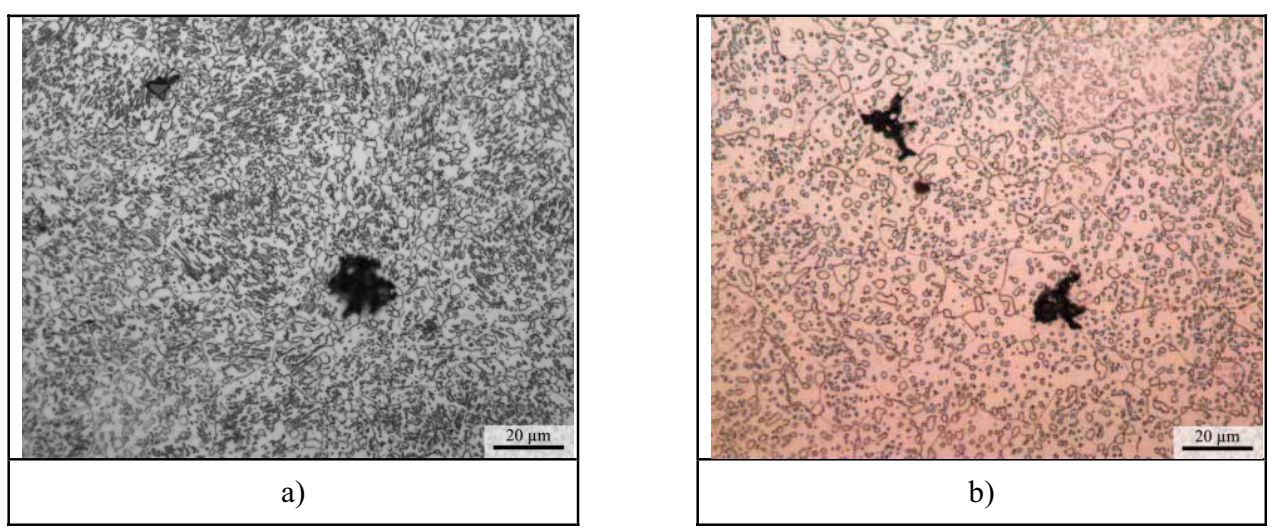

Fig. 5. Graphitization from non-martensitic structures. a) Structure of graphitized steel after annealing at $670^{\circ} \mathrm{C}$ for $110 \mathrm{hrs}$ from primary pearlitic-cementitic structure (related to specimen No.8). b) Structure of graphitized steel after annealing at $670^{\circ} \mathrm{C}$ for $110 \mathrm{hrs}$ from primary asreceived structure (related to specimen No.9).

It may be concluded by comparing figures $6 \mathrm{a}$ and $\mathrm{b}$ with figures $5 \mathrm{a}$ and $\mathrm{b}$ that graphitization from all three structures is done after partial spherodizing of carbides. Therefore it can be said that in the so-called steel the spherodizing process of carbides occurs before graphitization being dominant to it. By investigating the microstructure of specimen No.5 using SEM (figure 6b) which is extracted after the first changes in the length of the dilatometric specimen from graphitization transformation after annealing for 6.5 hours it can be concluded by EDX analysis that the presence of graphite particles in this specimen is approved (figure $6 c)$. On the other hand, the size of carbide particles in specimen No.5 is smaller than specimens No.7 and 8 which results in the increase of cementite's surface and therefore the surface of graphitization transformation and finally acceleration of the kinetics of this process in this structure.

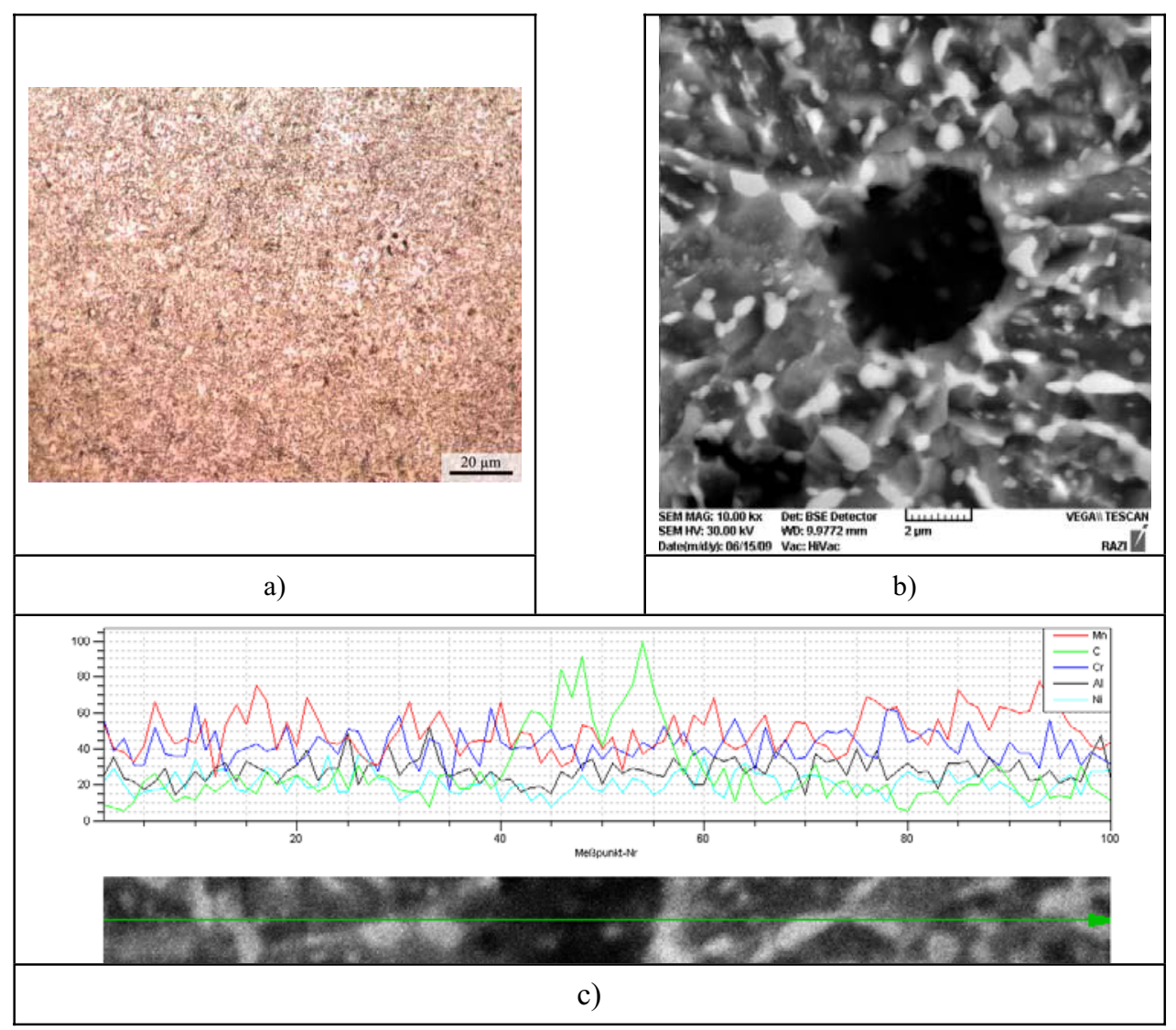


Fig. 6. Structure of dilatometric specimen after initial length change due to graphitization transformation after annealing at $670^{\circ} \mathrm{C}$ for $6.5 \mathrm{hrs}$ (related to specimen No.5). a) LOM image form specimen microstructure. b) SEM image from the same specimen. c) EDX and line scan analyze of a graphite particle and its around regions in specimen No.5.

By investigating the microstructures of graphitized specimens (figures $4 a$ and $b$ ) it is observed that most of graphite particles are formed on ferrite grain-boundaries. On the other hand, according to the value of $n$ which indicates the diffusion-controlled nucleation and growth, we can conclude that grain-boundary diffusion play a dominant role in this transformation. Therefore another factor which accelerates graphitization process from martensite structure compare to other structures is the formation of fine-grained ferrite in the structure and the increase of grain-boundaries as the paths of diffusion of carbon into graphite particles such that the size of ferrite grains in this structure are smaller than the as-received steel (figure 1) even after annealing for 60 hours (figures $4 a$ and $b$ ).

In addition by extracting the values of time for $\mathrm{X}=0.05$ from the dilatometric diagram of the three specimens which were quenched before performing the test in different environments we can calculate the times of the initiation of graphitization transformation in these specimens (table 3 ). It is observed that the initiation of graphitization transformation from martensite decreases by increasing the cooling power of quenching environment. Specimen No.6 shows the structure of steel during the initial graphitization periods (figure 7). Due to the fact that nucleation and growth of graphite particles from martensite structure is controlled by diffusion $(n=1.4)$, the direct effect of the increase of crystal defects and high-energy regions beside the meta-stability of martensite structure on increasing the number of stable graphite nuclei (figure 7) and increase of diffusion index as the controlling parameter in this transformation is explainable in comparison with other structures (figures $5 \mathrm{a}$ and $\mathrm{b}$ ) leading to the decrease of nucleation time and graphitization latency from martensite specimens compare to other structures.

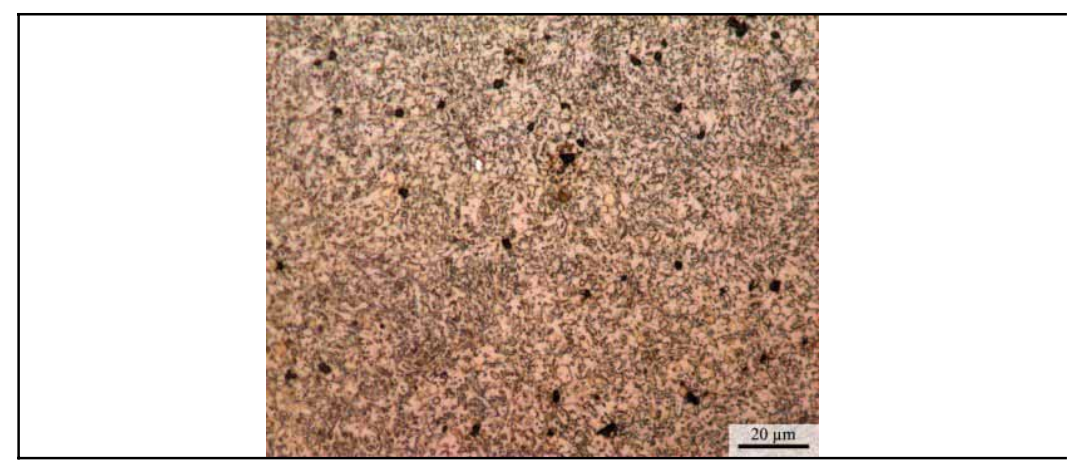

Fig. 7. Structure of graphitized steel after annealing at $670^{\circ} \mathrm{C}$ for $12 \mathrm{hrs}$ from primary martensitic structure (related to specimen No.6)

\section{Conclusions}

The results of this research show that the graphitization process from steel specimens with martensite structure follows Johnson-Mehl-Avrami relation and the value of $\mathrm{n}$ in this transformation is 2.4 which show diffusion-controlled nucleation and growth.

The acceleration of graphitization transformation from steel specimens with martensite structure compare to other structures is explainable from the viewpoints below:

The acceleration of diffusion process especially in the first stages of the annealing of martensite structure due to the presence of many crystal defects in this structure and also the increase of ferrite grain-boundaries formed from martensite structure compare to other structures

The formation of fine and almost spherical cementite particles formed due to the annealing of martensite structure during the first stages of annealing

The presence of more higher-energy susceptible regions for nucleation and coarsening of graphite particles in martensite structure compare to other structures 
The results show that the time of the initiation of graphitization transformation from martensite structure decreases with the increase of the cooling power of the quenching environment.

\begin{abstract}
Acknowledgments
The main part of these researches was done in laboratories of Metallurgical and Material Science Group of Ferdowsi University of Mashhad which requires our acknowledgment to their personnel for their assistance.

We also appreciate Mr. Ahad Zabet PhD and Part Sazan Co. for preparing some of the Optical Microscopic pictures. In addition we thank Mr. Payam Shayesteh and Mr. Ghasem Isa Abadi Bozchelouyi for performing some of the tests.
\end{abstract}

\title{
References
}

[1] J.H. Andrew, H. Lee, J. Iron Steel Inst. 165 (1950) 145.

[2] G.V. Smith, B.W. Royle, Trans. ASM 48 (1955) 320.

[3] A. Rosen, A. Taub, Acta Metall. 10 (1962) 501.

[4] H. Sueyoshi, K. Suenaga, Rev. Soc. Jap. Met. 42 (1978) 676.

[5] L.E. Samuels, Optical Microscopy of Carbon Steels, ASM, Metals Park, 1980.

[6] F. Ternon, Sv. Techn. Aerosp. Rep. 23 (1983) 21.

[7] V.I. Bidash, A.I. Prikhod'ko, Met. Sci. Heat Treat. 29 (1987) 116.

[8] H. J. Goldschmidt, Interstitial alloys. Butterworths, London (1967) 4, 41, 114 - 120.

[9] C.R. Austin, M.C. Fetzar, Trans. ASM 35 (1945) 485.

[10] R.H. Hickley, A.G. Quarrell, J Iron Steel Inst (1954) 178, 337.

[11] G.T. Higgins, G.V. Jeminson, J. Iron Steel Inst. 203 (1965) 146.

[12] J.E. Harris, J.A. Whiteman, A.G. Quarrel, Trans. AIME 233 (1965) 168.

[13] Hugh O. Pierson, Handbook of Carbon, Graphite, Diamond and Fullerenes Properties,

Processing and Applications, Consultant and Sandia National Laboratories (retired)

Albuquerque, New Mexico, Published by William Andrew Inc. (1993) 100-104.

[14] ASM Metals HandBook Volume 1, Properties and Selection: Irons, Steels and High-

Performance Alloys (1998) 13-194.

[15] A.R. Kiani-Rashid, D.V. Edmonds, Phase transformation study of aluminum-containing ductile cast irons by dilatometry, Materials Sci. \& Eng. A, Vol. 481-482C (2008) 752-756.

[16] Iwamoto Takashi, Murakami Toshiyuki, Bar and Wire Steels for Gears and Valves of Automobiles eco-friendly free cutting steel without lead addition-, JFE GIHO No. 4 (May 2004) 64-69.

[17] D.V. Edmonds, Proceedings of 15 th international congress on electron microscopy, Durban, South Africa, Physical, Materials and Earth Sciences, Microscopy Society of Southern Africa, Vol. 1. (2002) $667-8$.

[18] K. He, H.R. Daniels, A. Brown, R. Brydson, D.V. Edmonds, An electron microscopic study of spheroidal graphite nodules formed in a medium-carbon steel by annealing, Acta Materialia 55 (2007) 2919-2927.

[19] P, Rysh, Liteinor Proizvodstvo, No. 6 (1961).

[20] V.K. Titov, Liteinoe Proizvodstve, No. 11 (1961).

[21] F.K. Tkachenko, Izv AN SSSR, OTN, No. 1 (1963).

[22] E. N. Pogrebnoi, I. G. Kheifets, and N. E. Tsygankova, Influence of structural imperfections on the graphitization of white cast iron and steel, Translated from Metallovedenie i Termicheskaya Obrabotka Metallov, No. 4 (1966) 39-43.

[23] M. Avrami, Kinetics of Phase Change. I. General Theory, Journal of Chemical Physics (1939) 11031112.

[24] M. Avrami, Kinetics of phase change 2: Transformation-time relations for random distribution of nuclei, Journal of Chemical Physics (1940) 8:212-224.

[25] J.W. Christian, The Theory of Phase Transformations in Metals and Alloys, 2nd ed., Pergamon, Oxford (1975) 538-546. 